$\Phi=\Phi$

\title{
Study of lung function on construction workers
}

\author{
Shobha K.L ${ }^{1}$, Subbramaniam Venkatachalam ${ }^{2}$, Ashriina Nair ${ }^{2}$, Buwanesswaran Elangu ${ }^{2}$, Periyaiyadever \\ Samuganathan ${ }^{2}$, Barathi Subramanian ${ }^{1}$, Amita Shobha Rao ${ }^{3}$, Ramachandra L ${ }^{4}$ \\ ${ }^{1}$ Professor, Melaka Manipal Medical College (Manipal campus), Manipal University, Manipal, India \\ ${ }^{2}$ Undergraduate Medical Student Melaka Manipal Medical College (Manipal campus), Manipal University, Manipal, India \\ ${ }^{3}$ Associate Professor, Melaka Manipal Medical College (Manipal campus), Manipal University, Manipal, India \\ ${ }^{4}$ Professor,Department of Surgery, Kasturba Medical College, Manipal University, Manipal \\ *Corresponding author E-mail: shobhamicro@yahoo.com
}

\begin{abstract}
Lungs are one of the most vital organs which are responsible for gas exchange during respiration .Lung functions can be compromised in working environment especially at building construction work. The aim of the study was to assess the lung functions of the construction workers.

Material and Methods: Adult volunteers who had given consent with a field work experience of minimum 2 years were involved in the study. Validated questionnaire was given to them and the responses were collected .Peak flow meter measurement were also analysed.

Results: $(65.30 \%)$ smokers had a peak flow meter reading of less than 400L and plumbers were the group affected by decreased pulmonary function test followed by mason-helpers.

Conclusion: Morbidity among the construction workers varied with type of work at the construction site and comorbid factors such as smoking.
\end{abstract}

Keywords: Building Construction Workers; Pulmonary Function Test.

\section{Introduction}

Lungs are one of the most vital organs which are responsible for gas exchange during respiration, whereby it removes carbon dioxide from the blood, exchanging it with oxygen. Lung functions can be compromised due to various factors such as diseases, allergies and infections. Working environment is usually a factor as well, especially for those working at construction sites. However, most construction workers are unlikely to be aware of the state of their lungs and declining of their lung functions. While in fact, there have been studies indicating that those in the construction field tend to have a higher risk of respiratory problems. Construction workers are usually on a minimum wage and are unaware of their health issues. It is crucial to know the state of one's lungs and ways to decrease the risk of respiratory illness for the betterment of an individual. The aim of the study was to assess the lung functions of the construction workers.

\section{Materials and methods}

100 construction workers who had given consent and volunteered were involved in the study. Both males and females were included in the study. Inclusion criteria were study population in the age group of 18 to 50 years, males weighing $50-70 \mathrm{kgs}$ and females weighing $40-60 \mathrm{kgs}$, should have worked at least minimum of two years in the construction field. Exclusion criteria included history of cardiac arrest in the last 3 months, persons using inhalers and pregnant ladies A validated questionnaire consisting of sixteen questions which included smoking habits and demographic profile was given to subjects to complete and the data was collected and analyzed using Microsoft excel 2010 version. Lung function test was performed using Wright's Peak Flow Meter.

\section{Results}

Study population included 60 males and 40 females, Mean age of females was 25 years and 30 years for males. 56 workers were from Karnataka and the other 44 from Tamilnadu state. Out of the 100 workers, 49 subjects were smokers. 32(65.30\%) smokers had a peak flow meter reading of less than 400L (Normal range 400L$600 \mathrm{~L}$ ) and only $17(34.7 \%)$ had a peak flow meter reading of 400L-600L.

Association between type of field work and peak flow reading: Shows that mason-helpers $(20 \%)(10 / 52)$ were worst effected in the pulmonary lung function test with peak flow meter reading showing less than 200L. In the range of less than 400L reading, plumbers $(72.77 \%)(14 / 18)$ were worst effected with their decreased lung functions (Fig1) 


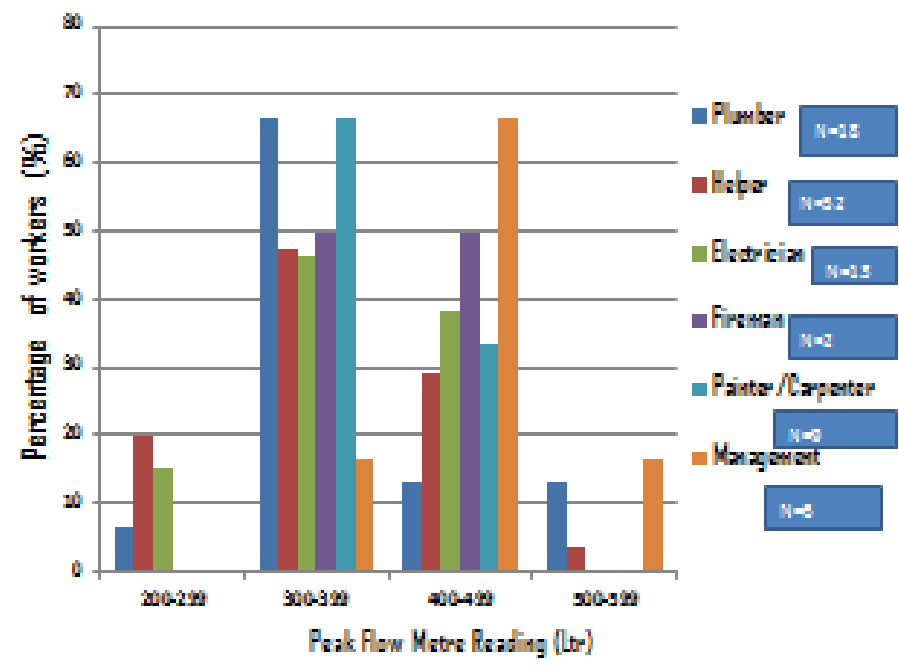

Fig. 1: Association between Field of Work and Place Flow Reading.

\section{Discussion}

The number of male workers were more than the female workers, ratio of male to female was $3: 2$, this could be because of risk of injury to females in the workplace and females avoiding heavy work, similar findings were correlated with the study conducted by (JessicaT Kubo et al.1994 Tobacco smoking is a major risk factor for cardiovascular disease, chronic obstructive pulmonary disease and some cancers. A quarter of smokers develop chronic obstructive pulmonary disease and smoking happens to be the fourth commonest cause of death worldwide (Scanlon P.D 2016) We found that peak expiratory flow rate was decreased significantly in smokers compared to non-smokers, $32(65.30 \%)$ smokers had a peak flow meter reading of less than 400L (Normal range $400 \mathrm{~L}-600 \mathrm{~L}$ ), P-Value $<0.05$. Our findings were in agreement with the findings of (Leonardo M Fabbri 2016) According to the study conducted by (Chhabra SR 2001, Zhang H 2003, Anong Tantisuwa 2014, James D. McCluskey 2014) smokers had decreased lung function test when compared to nonsmokers. Our study also opined this findings. One possible reason for the decrease in peak flow expiratory rate could be an inflammation which is common and a constant pathological finding in smokers. Studies conducted by (Monica Lucattelli et al . 2011) have reported that airway flow limitation occurs due to bronchial constriction caused by mediators of inflammation either directly or by increasing smooth muscle tone indirectly. All these changes promote wall thickening leading to airway narrowing and flow limitation. In addition to that, inflammation causes destruction of the alveolar walls attached to the airway contributing to further airflow limitation by deforming and narrowing the airway lumen which had reduced the pulmonary function. Study conducted by (Kathleen M et al.2012) showed plumbers were the worst effected group by decreased lung function as their occupational hazard. In our study we found $77.77 \%$ among plumbers had peak flow measurement less than $400 \mathrm{~L}$. Plumbers closely work as part of construction team with pipe-fitters and steamfitters on large-scale jobs and industrial projects. They may install plumbing systems in new construction or they may be called out to fix a problem with an existing system. The amount of plumbing work needed to be done at a construction site puts plumbers at risk of toxic asbestos exposure because of the number of asbestos containing products they use for material and for repair work. This finding was in concordance with the study conducted by (Døssing M 1990 \& Baur X 2015) Lung function impairment was one of the most common occupational respiratory problems associated with occupation dust exposures (Fell A.K 2003, Meo S.A 2006, Similee Johncee 2011, Marwan M. Draid 2015). Similarly we found that mason- helpers were the second common group effected with decreased lung function. A study conducted by (Dong XS et al .2015) showed similar results.

\section{Conclusion}

The study showed significant respiratory morbidity among the construction workers which varied with type of work at the construction site and comorbid factors such as smoking. Health education, wearing protective measures at workplaces and periodic health check-up can minimize the morbidity.

\section{References}

[1] Jessica T Kubo, Mark R Cullen,Manisha Desai et al : Association between employee and manager gender: impacts on gender-specific risk of acute occupational injury in metal manufacturing: BMC Public Health, 2013,13,1053 https://doi.org/10.1186/1471-2458-131053

[2] Scanlon PD. Respiratory function: mechanisms and testing. In Goldman L, Schafer AI, eds. Goldman's Cecil Medicine. 25th ed. Philadelphia, PA: Elsevier Saunders; 2016: chap 85

[3] Leonardo M.Fabbri: Smoking,not COPD, as the disease, New Engl.J Med 2016: 374:1885-1886 https://doi.org/10.1056/NEJMe1515508.

[4] Chhabra SK1, Rajpal S, Gupta R; Patterns of smoking in Delhi and comparison of chronic respiratory morbidity among beedi and cigarette smokers: Indian J of Chest Dis Allied Sci:2001:Jan-Mar: 43(1);19-26

[5] Zhang H, Cai B: The impact of tobacco on lung health in China:Respiratory 2003 Mar 8(1)17-21

[6] Anong Tantisuwat, Premtip Thaveeratitham: Effects of Smoking on Chest Expansion, Lung Function, and Respiratory Muscle Strength of Youths: J phys Ther Sci; 2014 Feb, 26(2) 167-170 https://doi.org/10.1589/jpts.26.167.

[7] James D. McCluskey, Stephen C. et al: Occupational health surveillance: Pulmonary function testing in emergency responders: $\mathrm{J}$ of Emerg trauma shock 2014 July- Sep 7(3) 180- 185 https://doi.org/10.4103/0974-2700.136861.

[8] Monica Lucattelli, Sanja Cicko, Tobias Müller et al : P2X7 Receptor Signaling in the Pathogenesis of Smoke-Induced Lung Inflammation and Emphysema: American J of Resp cell and molecular biology: Vol $\quad 44$ no3:2011:423-429 https://doi.org/10.1165/rcmb.2010-0038OC

[9] Kathleen M. Donohue, Eric A. Hoffman, Heather Baumhauer et al: Cigarette smoking and airway wall thickness on CT scan in a multiethnic cohort: The MESA Lung Study: Respiratory medicine: Vol 106; issue $12 ; 2012: \quad 1655 \quad-1664$ https://doi.org/10.1016/j.rmed.2012.08.006.

[10] Døssing M, Groth S, Vestbo Jet al : Small-airways dysfunction in never smoking asbestos exposed Danish plumbers: Inter.arch Occupant environmental health: 1990: 62(3): 209-212

[11] Baur X, Wilken D: Effect of asbestos fibre dust exposures on lung function--a systematic review Pneumologie: 2010 Feb;64 (2):81-11 https://doi.org/10.1055/s-0029-1243815. 
[12] Fell A.K., Thomassen T.R., Kristensen P et al. Respiratory symptoms and ventilator function in workers exposed to Portland cement dust. J. Occup. Environ. Med. 2003;45:1008-1014 https://doi.org/10.1097/01.jom.0000083036.56116.9d.

[13] Meo S.A. Lung function in Pakistani wood workers. Int. J. Environ. Health Res. 2006;16:193-203 https://doi.org/10.1080/09603120600641375.

[14] Similee Johncee, K.T Ajay, G. Dyanakumar et al: Dust exposure and lung function impairment in construction workers: J Physiological Biomed Sci:2011:24(1): 9-13

[15] Marwan M. Draid, Khaled M. Ben-Elhaj, Ashraf M. Ali et al: Lung Function Impact from Working in the Pre-Revolution Libyan Quarry Industry: Int J of Environ Res Public Health: 2015 May; 12(5): 5006-5012. https://doi.org/10.3390/ijerph120505006.

[16] Dong XS, Wang X, Largay JA et al : Long-term health outcomes of work-related injuries among construction workers--findings from the National Longitudinal Survey of Youth: Am J Int Med: 2015 Mar;58(3):308-18 